\title{
Schwannoma of the Buccal Mucosa: Report of A Case In A Rare Location
}

Suchitra ${ }^{1}$, Sulabha A N², Sameer Choudhari ${ }^{3}$

Quick Response Code

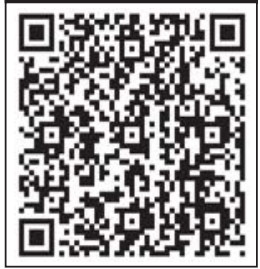

\section{doi: $10.5866 / 2014.641710$}

${ }^{1}$ Assistant Professor

Department of Oral \& Maxillofacial Pathology

Al-Ameen Dental College \& Hospital, Bijapur-586108

${ }^{2}$ Professor

Department of Oral Medicine \& Radiology

Al-Ameen Dental College \& Hospital, Bijapur-586108 ${ }^{3}$ Reader

Department of Oral \& Maxillofacial Surgery

Al-Ameen Dental College \& Hospital, Bijapur-586108

\section{Article Info:}

Received: J uly 8, 2014

Review Completed: August 7, 2014

Accepted: November 10, 2014

Available Online: J anuary, 2015 (www.nacd.in)

(c) NAD, 2015 - All rights reserved

\section{Email for correspondence:}

suchipra75@rediffmail.com

\begin{abstract}
:
Schwannoma are relatively uncommon benign neoplasm of the Schwann cells. Their incidence of intra oral location is still very less common. Tongue being the common site intraorally, schwannomas of buccal mucosa is rarely reported. They are rarely included in the differential diagnosis of other benign neoformations of epithelial tissue as well as connective tissue especially in this site. The Schwannoma are usually solitary. This case report is about a 45 year ol d male patient with duration of one year diagnosed based on clinical and histopathological examination and treated surgically.
\end{abstract}

Key words: Buccal Mucosa, Neurilemmoma, Schwannoma.

\section{Introduction}

Schwannoma, a benign neoplasm of peripheral nerve sheath, rarely occurs in the oral cavity (1\%): the most common form is a unilobular tumor on the dorsum of the tongue whilst the vestibular mucosa is a rare location. Schwannoma occurring in vestibular mucosa, alveolar mucosa have been reported but those of buccal mucosa are rarely reported. The present case report presents a Schwannoma of buccal mucosa.

\section{CASE REPORT:}

A 45 year old male patient presented to the dental clinic with a history of growth in relation to inner aspect of his left cheek region since one year. The lesion was initially small in size and showed gradual increase. There was no associated pain or regression in size. On clinical examination a solitary well defined sessile lesion of size $1.5-2 \mathrm{~cm}$ was noted in the left buccal mucosa along the line of occlusal plane. The lesion was firm and not tender. Superficially areas of ulceration were evident (Figure 1). Based on the clinical findings a diagnosis of fibroma was made and the lesion was surgically excised under local anesthesia and sent for histopathological examination. The lesion healed uneventfully. Histopathol ogy revealed a well defined tumor mass comprised of spindle shaped cells with

\section{InDian Journal OF Dental AdVAncements Journal homepage: www. nacd. in}




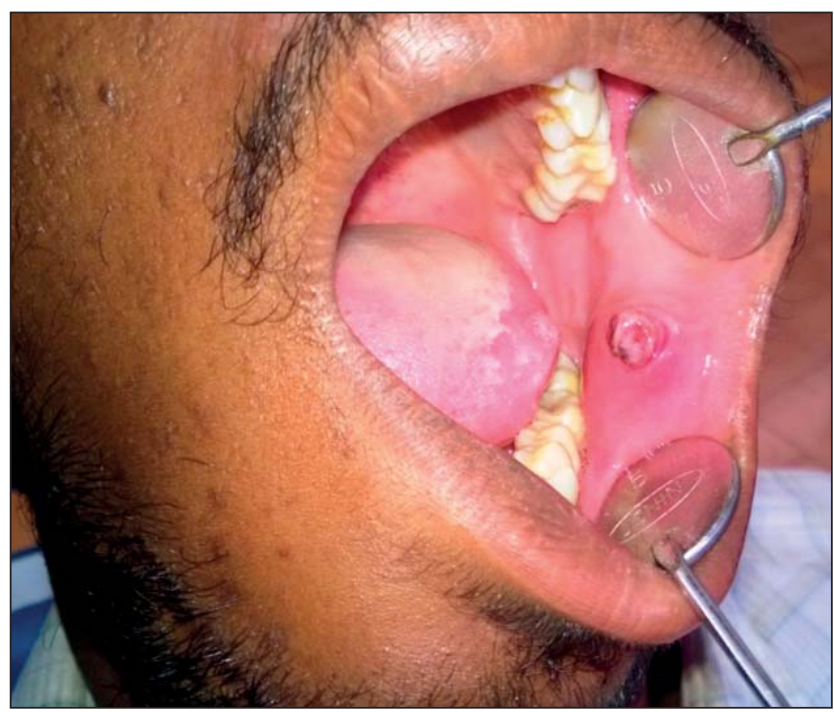

Figure 1: Clinical photograph showing a solitary well defined sessile lesion of size $1.5-2 \mathrm{~cm}$ in the left buccal mucosa along the line of occlusal plane.

arrangements of Antoni $A$ and $B$ type tissue (Figure 2). The first Antoni A pattern showed closely arranged bundles of schwann cells with spindleshaped nuclei which were aligned in parallel rows, which formed a typical palisading pattern around acellular, amorphous, eosinophilic masses, which represented the verocay bodies. The second Antoni B pattern showed disorganized, hypocellular areas of fusiform cells which were distributed in a random fashion Very few blood vessels were appreciated as the mass predominantly had Antoni A type tissue. A final diagnosis of Schwannoma was rendered. The patient is fine and there is no history of recurrence after a one year follow up period.

\section{DISCUSSION:}

Schwannomas, also referred to as neurilemmomas, neurinomas or perineurial fibroblastoma are benign, non recurring encapsulated nerve sheath tumor composed of Schwann cells. ${ }^{1}$ The embryological derivation of these Schwann cells is during the fourth week of development from a specialized population of ectomesenchymal cells of the neural crest. These cells detach from the neural tube and migrate into the embryo. These cells form a thin barrier around each extracranial nerve fiber and wrap larger fibers with an insulating membrane, the myelin sheath. This enhances nerve conduction. As the nerves exit the brain and spinal cord, there is a change between

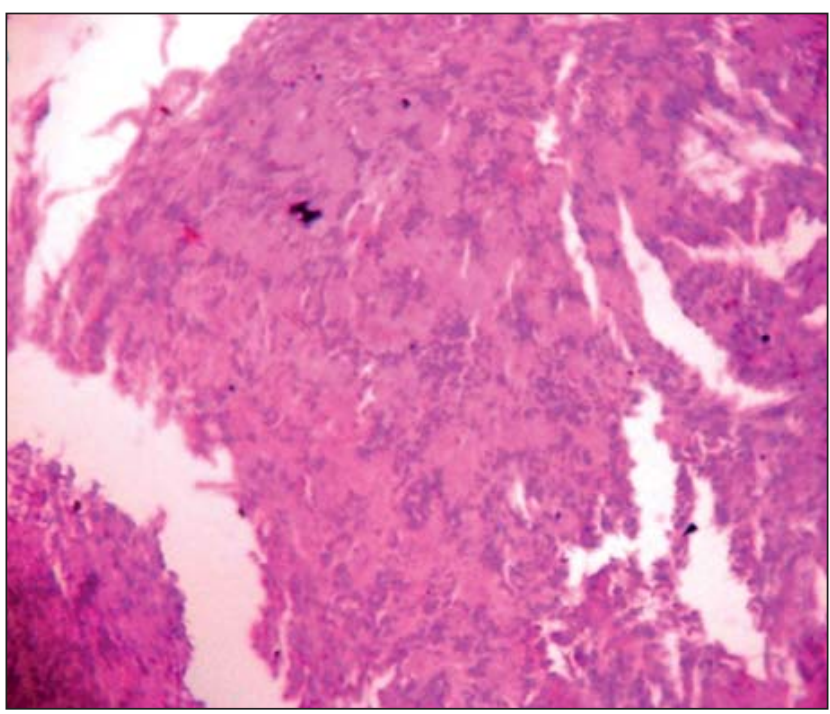

Figure 2: $\mathrm{H}$ and $\mathrm{E}$ stained section showing spindle shaped cells with arrangements of Antoni A and B type tissue (X10).

myelination by oligodendrocytes to myelination by Schwann cells. ${ }^{2}$ Schwannomas arise when proliferating Schwann cells form a tumor mass encompassing motor and sensory peripheral nerves. They arise at any age, but the peak incidence is between third and seventh decades of life without any gender predilection. Almost $50 \%$ of the cases have direct relation with the involved nerve. Their distribution is wide including diverse locations such as cranial nerves, bone, gastrointestinal tract and slight predilection for distal extremities. The vestibular schwannomas on bilateral side is associated with neurofibromatosis type II.

About one third of all Schwannoma cases are found in head and neck region. ${ }^{2,3}$ Among them about $1 \%$ of cases show intraoral origin. Extracranially, neurilemmomas are found most commonly in the neck, with majority of the cases in carotid triangle. ${ }^{4}$ The sites having greatest predilection are head, neck, flexor surfaces of upper and lower extremities. Among intraoral location tongue is the common site followed by palate, floor of the mouth, gingiva, lips and buccal mucosa. ${ }^{5}$ The present case was located in the buccal mucosa where clinical differential diagnosis commonly includes other benign proliferations such as mucoceles, fibromas, and lipomas.

M ost of the cases areasymptomatic and usually are less than $5 \mathrm{~cm}$ in diameter. The tumor may also 
present itself as a unilocular, intraosseous lesion most commonly in the posterior mandible, and can produce pain and paresthesia.

As a diagnostic and treatment tool, ultrasound, computed tomography, or magnetic resonance imaging may be helpful for estimation of tumor margin and determination of whether there is infiltration of surrounding structures. Ultrasound findings usually show homogenous, hypoechoic features. Computed tomography findings show homogenous soft tissue density mass with a clear margin. ${ }^{5}$

Histopathological findings of the present case were consistent with schwannomas which comprise of thin fibrous capsule and tumor proliferation formed by Antoni type A and Antoni type B tissue arrangement. Antoni type A tissue is characterized by Schwann cells that are closely packed, forming bundles or arranged in rows with elongated, palisaded nuclei. Free bands of amorphous substance between the rows of nuclei constitute the so called Verocay bodies There are normal mitotic figures but do not exceed 5per 10 high power fields. While in the Antoni B tissue it has less number of cells and less organization, where the fusiform cells are widely separated, dispersed in a loose and random fashion with a network of delicate reticulated fibers. ${ }^{1}$ It shows blood vessels with thick hyaline walls. Associated nerve is occasionally evident stretched over the capsule. Progressive degenerative changes, most often reflecting lesional duration or a frequently traumatized location are initial focal hyalinization, stromal hemorrhage, cystic change and calcification.

All schwannomas are diffusely immunoreactive for S-100 protein. ${ }^{6}$

Ultrastructural features include small cell bodies and elongated, interdigitating cytoplasmic processes invested by a complete external lamina which is often reduplicated. These processes are commonly connected by desmosome-like junctions. Organelles are relatively few and non-specific. There are often bundles of long-spaced collagen called Luse bodies in the stroma. ${ }^{7}$ Recent studies on genetic analysis have revealed monosomy 22 or loss of $22 q$ material, consonant with loss of one of the NF 2 gene alleles. $^{7}$

\section{CONCLUSION:}

Schwannomas though rare in occurrenceshould be included in the differential diagnosis of lesions of buccal mucosa. Thorough search for theselesions in other locations should also be done to rule out the association of neurofibromatosis. Final diagnosis is based on clinical, histopathological and immunohistochemical examination.

\section{REFERENCES:}

1. Martins MD, de J esus LA, Fernandes KPS, Bussadori SK, Taghloubi SA, Martins MAT. Intra-oral schwannoma: Case report and literature review. Indian J Dent Res 2009; 20:121-125.

2. Pfeifle R, Baur DA, Paulino A, Helman J. Schwannoma of thetongue: Report of two cases. J Oral Maxillofac Surg 2001; 59:802-804.

3. Kun Z, Qi DY, Zhang KH. A comparison between the clinical behavior of neurilemomas in the head and neck and oral and maxillofacial region. J Oral Maxillofac Surg 1993; 51:769-771.

4. Batsakis J G: tumors of the peripheral nervous system, in tumors of the head and neck (edition2) Baltimore. M D,Williams \& Wilkins,1979,pg 313-326.

5. Chrysomali E, Papanicolaou SI, Dekker NP, Regezi J A. Benign neural tumors of the oral cavity: A comparative immunohistochemical study. Oral Surg Oral Med Oral Pathol Oral Radiol Endod 1997; 84:381-390.

6. Enzinger FM, Weiss SW. 3rd ed. Soft tissue tumors. St Louis: MO Mosby; 1995, pg 821-850.

7. Christopher D M Fletcher. Third edition. Diagnostic histopathology of tumors. Vol 2. Churchill-livingstone Elsevier; 2007 pg 1736-1740.

\section{Gain quick access to our journal online View our journal at www.nacd.in}

